\title{
Estudos sobre Inglês como Língua Franca no Brasil (2005 -2012): uma metassíntese qualitativa
}

Studies on English as a Lingua Franca in BRAZil (2005-2012): A QUALITATIVE METASYNTHESIS

\section{Marcella BORDINI* Telma GIMENEZ**}

Resumo: Este trabalho apresenta um mapeamento de estudos sobre o inglês como língua franca global, publicados no Brasil entre 2005 e 2012. Buscas no Banco de Teses da CAPES, Google acadêmico e alguns periódicos qualificados da área de Letras/Linguística Aplicada foram realizadas com foco em inglês como língua franca, inglês como língua global, inglês como lingua internacional e inglês como língua multinacional, além de um livro específico, totalizando 67 trabalhos. Por meio de uma revisão sistemática da literatura e uma metassíntese qualitativa dos estudos localizados (SARNIGHAUSEN, 2011), foi possível verificar que se entende, predominantemente, o conceito de inglês como língua franca como um contexto de uso entre falantes de inglês, principalmente (mas não exclusivamente) entre não nativos, e que essa perspectiva é relevante para o ensino; entretanto, na ausência de pesquisas empíricas de interações envolvendo brasileiros, a formação de professores tem como suporte básico a literatura internacional. Em função dessa lacuna, os educadores brasileiros podem contar com uma produção essencialmente de natureza ensaística.

Palavras-chave: Mapeamento de estudos. Contexto brasileiro. Inglês como língua franca.

\footnotetext{
* Graduada em Letras - Inglês/Respectivas Literaturas e Habilitação em Língua e Cultura Francesas pela Universidade Estadual de Londrina. Mestre (2013) em Estudos da Linguagem pela UEL. Contato: bordini.marcella@gmail.com.

** Doutora (1994) pelo Departament of Linguistics and Modern English Language da Lancaster University, Inglaterra. Professora Associada da Universidade Estadual de Londrina. Pesquisadora apoiada pelo CNPq. Contato: tgimenez@uel.br.
} 
Abstract: This work aims at presenting an overview of studies focusing on English as a global lingua franca published in Brazil between 2005-2012. The following sources were scrutinized: CAPES Database of Theses, Scholar Google and highly qualified Brazilian journals of Languages/Applied Linguistics using the key terms: English as a lingua franca, English as a global language, English as an international language and English as a multinational language. Additionally, a specific book was included, totalling 67 studies. Through a systematic literature review and a qualitative metasynthesis of the studies (SARNIGHAUSEN, 2011), we concluded that in the majority of the studies the lingua franca concept is understood as a context of language use, mainly, but not exclusively, between non-native speakers of English. The themes suggest the predominance of pedagogical concerns. However, in the absence of corpus-based investigations which include Brazilians, teacher education programs have to rely on essay based literature, which predominates in our country.

Key words: Literature review; Brazilian context; English as a lingua franca.

O interesse por pesquisas sobre ILF na América Latina até o momento tem sido pequeno, provavelmente por causa da presença de outra língua franca 'global' na região, o espanhol (embora não seja a língua nacional do Brasil). Mesmo os poucos pesquisadores da região que se dedicam ao ILF tendem a focar em questões mais amplas, ao invés de locais (e. g. Rajagopalan 2009). Talvez, assim como ocorreu na China na época das Olimpíadas de Pequim em 2008, o interesse pelo ILF aumente na América Latina, como resultado dos Jogos Olímpicos, que serão sediados no Rio de Janeiro em 2016. ${ }^{1}$

${ }^{1}$ Latin America's research interest in ELF has so far remained lukewarm, probably because of the presence in the region of another 'global' lingua franca, Spanish (albeit not the national language of Brazil). Even the few scholars in the region who do engage with ELF tend to focus on the wider rather than local issues (e.g. Rajagopalan 2009). Perhaps, though, as happened in China's case when the 2008 Olympic Games were held in Beijing, interest in ELF will grow in Latin America as a result of the 2016 Olympic Games in Rio de Janeiro. JENKINS; COGO; DEWEY, 2011, p. 285, tradução nossa). 


\section{Introdução}

O inglês vem sendo estudado a partir de diversas perspectivas: como língua nativa (ENL - English as a Native Language), falada nos países do chamado Círculo Interno ${ }^{2}$ como segunda língua (ESL - English as Second Language), em países do Círculo Externo como língua estrangeira (EFL English as a Foreign Language), em países do Círculo em Expansão como uma língua policêntrica, desenvolvendo diversas variedades, como é o caso dos World Englishes (WE), e como uma língua franca global (ELF - English as a Lingua Franca). Para alguns, trata-se de um novo fenômeno linguístico World English, ou inglês mundial (RAJAGOPALAN, 2011). O inglês como língua franca (ILF) vem sendo objeto de estudos, especialmente no contexto europeu (FIRTH, 2009) e vem ganhando terreno na Linguística Aplicada, conforme demonstram os trabalhos apresentados nas seis edições já realizadas do Congresso Internacional de Inglês como Língua Franca e publicados no Journal of English as a Lingua Franca, lançado em 2012.

A despeito dessa disseminação, o campo é permeado por controvérsias. A primeira delas diz respeito à sua conceituação e a segunda, à pertinência de descrever esse fenômeno sociolinguístico como uma nova variedade de inglês. Se, por um lado, há os que defendem ser esta uma nova variedade ainda a ser descrita léxico-gramaticalmente e fonologicamente (JENKINS, 2006; SEIDLHOFER, 2001); por outro, há os que defendem ser a denominação apenas uma maneira de se referir às situações de uso da língua que envolvem falantes não nativos, hoje em maior número que falantes nativos (BERNS et al., 2011; PRODROMOU, 2007, 2008).

2 Para Kachru (1985), os falantes de inglês estão divididos em três círculos concêntricos - o "Inner Circle", ou Círculo Interno, no qual estão presentes os países falantes de inglês como língua materna, como é o caso dos Estados Unidos, Inglaterra, Canadá, etc.. O "Outer Circle", ou Círculo Externo, o qual é representado por países que adotam o inglês como segunda língua, como é o caso da Índia, Cingapura, Filipinas, dentre outros. E, por fim, o "Expanding Circle”, ou Círculo em Expansão, o qual compreende os países que adotam o inglês como língua estrangeira, como é o caso de Brasil, Rússia, China, Japão, dentre outros. Como o próprio nome já diz, o círculo em expansão está num crescente aumento, ou seja, cada vez mais e mais pessoas se apropriam da língua inglesa, a fim de atender aos seus interesses. 
A discussão do ILF, portanto, se pauta por diversas perspectivas. A expansão da língua inglesa no mundo é parte da contextualização de seu uso, que não pode ser compreendida senão no quadro da globalização enquanto fenômeno econômico, político e cultural. As reflexões sobre ILF têm sido produzidas especialmente no contexto europeu ou norte-americano, enquanto que a América Latina ainda carece de estudos, mesmo apresentando alguns dados incipientes sobre o inglês utilizado localmente (FRIEDRICH; BERNS, 2003); apenas recentemente começou a fazer parte da agenda de pesquisa no Brasil (vide, contudo, CALVO; EL KADRI, 2011; GIMENEZ; CALVO; EL KADRI, 2013; BORDINI, 2013).

Observa-se uma carência de reflexões sob uma perspectiva de autores brasileiros que reflitam o olhar de usuários e aprendizes em contexto do "Círculo em Expansão" a respeito da língua franca global. Dado que o assunto é relativamente novo, faz-se necessária uma revisão sistemática da literatura que englobe as pesquisas realizadas no contexto brasileiro, a fim de identificar os temas por elas tratados, os contextos de pesquisa e suas implicações pedagógicas. Isto permitirá que se tenha conhecimento sobre as pesquisas realizadas em nosso país, dando-lhes visibilidade e possibilitando interlocuções com estudos realizados em outros países.

Neste texto apresentamos um mapeamento dos estudos sobre inglês como língua franca no período de 2005 a 2012, conforme desenvolvido por Bordini $^{3}$ (2013). Os objetivos específicos da pesquisa foram: a) recuperar estudos sobre ILF, publicados no Brasil no período de 2005 a 20124; b) analisá-los de modo a estabelecer seus temas, seus contextos de pesquisa, e as relações entre as conclusões e implicações pedagógicas; c) indicar rumos para futuros estudos, cujos objetivos incluam encaminhamentos pedagógicos para o ensino e/ou formação de professores de língua inglesa.

Na primeira parte do artigo, apresentamos uma breve contextualização do ILF e suas controvérsias; na segunda, descrevemos a metodologia da pesquisa e, por fim, discutimos os resultados da análise.

${ }^{3}$ Marcella Bordini é uma das autoras desse trabalho e apresentou em sua dissertação de Mestrado (2013) os dados detalhados do mapeamento dos estudos nacionais sobre o ILF (inglês como língua franca).

${ }^{4}$ No Portal da CAPES estavam disponíveis apenas as dissertações e teses até o ano de 2011. 


\section{Inglês como Língua Franca (ILF)}

Há pouco mais de uma década, Seidlhofer $(2001)^{5}$ definiu o ILF como uma língua sem falantes nativos, o que não foi aceito sem contestação. Posteriormente, em 2005, admitiu que as interações em ILF não impedem a presença de falantes nativos da língua inglesa, embora seu interesse seja nas características da língua falada pelo não nativo. Em seu trabalho mais recente, Seidlhofer (2011, p. 7) define o ILF como "qualquer uso do inglês entre falantes de diferentes línguas maternas, para os quais o inglês é o meio comunicativo de escolha, e frequentemente a única opção". ${ }^{6}$

Desse modo, a questão nativo versus não nativo toma fortes contornos em ILF. Para Sifakis (2007), o ILF representa principalmente o inglês utilizado na comunicação entre falantes não nativos. Este tipo de interação tem sido tratado na literatura no que se pode classificar em duas categorias: a) primária: os estudos que buscam regularidades nas amostras de ILF; b) secundária: diz respeito às preocupações atitudinais, culturais, políticas, históricas e pedagógicas desse uso.

No tipo de categoria primária se encontra Seidlhofer, com a proposta do $\mathrm{VOICE}^{7}$ (Vienna-Oxford International Corpus of English), um corpus hospedado na Universidade de Viena (Áustria), que permitiria buscar as regularidades do Inglês usado especialmente no contexto europeu, mas que poderia ser expandido para outros lugares ${ }^{8}$. Essa codificação contribuiria para o questionamento da hegemonia das normas dos falantes nativos nos

${ }^{5}$ Seidlhofer (2001, p. 146, tradução nossa) define língua franca, como "um sistema linguístico adicional que serve como um meio de comunicação entre falantes de diferentes línguas maternas, ou uma língua com a qual membros de diferentes comunidades de fala podem se comunicar entre si, mas que não é língua materna de nenhum deles - uma língua que não possui falantes nativos."

${ }^{6} \mathrm{ELF}$ as any use of English among speakers of different first languages for whom English is the communicative medium of choice, and often the only option. (SEIDLHOFER, 2011, p. 7, tradução nossa).

7 Para maiores informações, acessar <http://www.univie.ac.at/voice/>.

${ }^{8}$ Este corpus tem como finalidade registrar as ocorrências frequentes das variações da língua, e conta com a participação de falantes adultos fluentes, de diversas áreas profissionais e que utilizam a língua inglesa como seu meio de comunicação, uma vez que estes possuem diferentes línguas maternas. 
mais variados contextos e enfatizaria a legitimidade da variedade utilizada por diferentes comunidades de fala.

Dewey e Jenkins (2010) enfatizam que o inglês como língua franca não é somente um uso legítimo da língua, mas também um aspecto característico particular dessa língua no mundo globalizado. Além disso, os autores afirmam que é prematura a ideia de descrever as inovações do ILF como um tipo de variação linguística, uma vez que ainda são incipientes pesquisas que buscam caracterizar o ILF como uma variedade de inglês. Também partilhando da visão de que ILF é uso e não variedade, Park e Wee (2011) argumentam que a língua é fluida, dependente de seus falantes para existir e, portanto, não havendo uma comunidade de fala específica (os falantes de inglês estão espalhados pelo mundo), a língua se caracteriza como prática social, emergente da necessidade de comunicação.

Como se pode inferir do que foi apresentado até aqui, há um debate em curso sobre o ILF. A polêmica pode ser tratada em torno de duas grandes propostas: a) a de que o ILF seria uma variedade e, portanto, poderia ser codificado; b) a de que o ILF representa o contexto de uso da língua e não uma variedade a ser codificada.

\subsection{ILF: variedade ou uso?}

Prodromou $(2007,2008)$ afirma que o ILF não é uma variedade distinta do inglês, e os argumentos que defendem esta variedade não passam de falácias. Com relação à primeira falácia, o autor reconhece as variedades como interligadas às normas padrão da língua inglesa. A segunda falácia refere-se à natureza da comunidade do ILF: este difere em sua essência das comunidades de fala onde o inglês se faz presente como segunda língua (L2) e é difícil ver como esses grupos poderiam convergir linguisticamente. Outra falácia detectada pelo autor refere-se à ideia de codificação do ILF: para ele, é muito prematura a ideia de sistematizar um núcleo linguístico para este inglês utilizado, em sua maioria, entre falantes não nativos. Assim, para o autor, é nítido que o ILF não representa uma entidade fixa, e sim uma resposta dinâmica às necessidades locais das pessoas envolvidas, não como um produto monológico, mas dialógico, o qual modula a escolha e uso linguísticos. Para ele, a diversidade dos falantes de inglês no mundo é imensa, o que impossibilita a codificação do inglês como língua franca, uma vez que existem processos variados de interação. 
Visão semelhante tem Ferguson (2009), ao afirmar que a codificação não é a mais apropriada para a legitimação do falante não nativo como usuário competente do inglês. Para o autor, codificar o ILF significa criar outro mecanismo de exclusão, assim como faz o inglês padrão. Logo, a forma de resistência mais eficaz à ideologia da língua padrão não significa necessariamente a construção de um padrão alternativo.

Berns et al. (2011) defendem ser o ILF uma questão de uso e não uma variedade específica. Para os autores, o ILF não representa uma variedade em si, mas contextos de uso da língua, definidos por fatores extralinguísticos. Ressaltam que é necessário considerar alguns aspectos das interações em ILF, se este for tomado como um contexto de uso: a) quem está interagindo?; b) por que estão interagindo?; c) qual o assunto em pauta?; d) qual o gênero desta amostra comunicativa? Para os autores, são os aspectos pragmáticos que deveriam constituir o cerne das pesquisas no campo do ILF (BERNS et al., 2009, 2011).

Por outro lado, Seidlhofer (2004) aponta recorrências linguísticas nas interações em ILF, como: a ausência do $-s$ na terceira pessoa do presente singular; a confusão entre os pronomes relativos (who/which), omissão dos artigos definido/indefinido, quando eles existem, e sua inserção quando não ocorrem nas normas do inglês nativo; uso das tag questions de forma inadequada pelas lentes do falante nativo; inserção de preposições redundantes; uso excessivo de verbos de alta generalização semântica; substituição de construções infinitivas por "I want that"; excesso de explicitação como em "black color", em vez de simplesmente utilizar black, entre outros. Também inexiste preocupação em se adequar às normas do falante nativo. Além disso, as interações em ILF parecem ser cooperativas e ricas em apoio mútuo, pois se configuram como situações nas quais os participantes podem expressar a sua identidade e a sua bagagem cultural.

Firth (2009) afirma que a maioria dos trabalhos embasados no ILF, com foco em características discursivas e pragmáticas, mostraram haver alto grau de interação, cooperação, busca por um consenso e afinidade, e as situações de mal entendidos se apresentam como raras nos contextos nos quais o inglês funciona como uma língua franca. De fato, pesquisas arroladas por Jenkins, Cogo e Dewey (2011) indicam que aspectos pragmáticos são temas comuns nas pesquisas. Jenkins (2000) traz como evidência pragmática o LFC - Lingua Franca Core - Núcleo Central da Lingua Franca, o qual representa uma espécie de núcleo linguístico responsável por focar nas 
regularidades da língua falada por não nativos, ou seja, identifica quais aspectos interferem ou não na inteligibilidade da comunicação. Para Jenkins (2006), nas interações em ILF, faz-se necessário o ajuste da variedade local, a fim de se tornar inteligível no momento da comunicação com os outros interlocutores. No entanto, não há ainda evidência suficiente para se saber qual a extensão do que constitui o núcleo do ILF.

A diversidade de entendimentos do que seja ILF atesta a emergência da área, sugerindo que apenas em pesquisas que busquem elucidar quais são esses entendimentos de modo contextual e sócio-historicamente localizados se poderá ter melhor compreensão de sua dimensão. Enquanto o debate sobre a natureza de ILF prossegue, educadores em diferentes partes do mundo têm sido chamados a considerar essa perspectiva em seu ensino, o que discutiremos na seção seguinte.

\subsection{Ensino de inglês na perspectiva do ILF}

Seidlhofer (2004) aponta que, devido à ausência de suficiente trabalho descritivo em ILF, professores continuam adotando materiais cujo foco é o inglês americano/britânico. A mesma pesquisadora faz uma crítica ao modelo atual de ensino de línguas, o qual tem como responsabilidade alterar a visão monocêntrica, monocultural, monolíngue, para uma educação que aborde aspectos relativos ao pluricentrismo, multiculturalismo, multilinguismo, ou seja, já é tempo de modificar os moldes tradicionais de ensino:

Uma questão que deve ser urgentemente explorada é a de qual 'inglês' está sendo ensinado nesta era global emergente, como este se enquadra nas preocupações sócio-políticas e socioeconômicas discutidas na profissão, e qual a sua relevância para o ensino nas salas de aula do mundo inteiro.' (SEIDLHOFER, 2001, p. 135).

Jenkins (2006) afirma que parece existir um consenso entre professores e aprendizes sobre qual variedade de inglês se deve ensinar e aprender: não

${ }^{9}[\ldots]$ a question in urgent need of exploration is just what the 'English' is that is being taught and learnt in this emerging global era, how it squares with the socio-political and socioeconomic concerns discussed in the profession, and what its relevance is for the subject taught in classrooms all over the world. (SEIDLHOFER, 2001, p. 135, tradução nossa). 
apenas uma variedade (padrão - americana ou britânica), mas sim, outras variedades que não são disseminadas amplamente ao redor do globo. Erling (2005) se alia a essa visão e afirma que uma comunicação bem sucedida, na visão do ILF, não pode mais partir das normas dos falantes nativos, uma vez que estes são minoria se comparados aos falantes de inglês do mundo.

Se o ILF não é uma variedade, não pode se apresentar como uma escolha a ser contemplada juntamente com aquelas já codificadas. Enquanto uso, educadores precisariam ter contato com os resultados de pesquisas que têm procurado documentar as regularidades de diferentes interações envolvendo diversos contextos comunicativos. Nesse sentido, parece fundamental a existência de corpora (e.g. VOICE, ALFA) que permitam a exploração de aspectos linguístico-discursivos presentes nessas interações. Assim, o ensino de uma variedade ou mais de uma variedade já codificada poderia ser complementado por resultados desses estudos, de modo a proporcionar aos aprendizes oportunidades de conhecer a língua realmente em situações de uso.

A fim de compreender o que pesquisadores brasileiros sensíveis a essas discussões discutiram em seus trabalhos, apresentamos, a seguir, o mapeamento realizado.

\section{Metodologia da Pesquisa}

\subsection{Da sua natureza}

Este estudo aborda o levantamento de trabalhos nacionais realizados no campo da Linguística Aplicada, cuja temática é o ILF, no período de 2005 a 2012. O levantamento desses trabalhos foi realizado de julho a agosto de 2012, e atualizado em fevereiro de 2013. Como estratégias de busca em todas as fontes pesquisadas, foram utilizadas as palavras-chave: "inglês como língua franca" (ILF), "inglês como língua global" (ILG), "inglês como língua internacional" (ILI) e "inglês como língua multinacional” (ILM).

Embora ciente da multiplicidade de termos adotados (e.g. RAJAGOPALAN, 2012), nosso interesse específico era com a nomenclatura língua franca, visto que representa uma visão particular da língua inglesa, na qual os falantes não nativos são alçados à condição análoga a de falantes nativos. As demais formas (global, internacional e multinacional) foram também investigadas, em função de seus sentidos poderem se aproximar ao de ILF. 
O levantamento bibliográfico foi feito por meio de uma revisão sistemática dos trabalhos. Para tanto, foi tomado como base o protocolo de ações baseado em Sarnighausen (2011):

- Parâmetro Temático - ILF;

- Critérios de inclusão - textos com foco no contexto de uso do inglês ou no ensino-aprendizagem pela perspectiva de ILF. Os textos que tratavam do inglês de forma periférica foram excluídos. Foram somente considerados textos publicados no Brasil;

- Parâmetro linguístico - Português ou Inglês;

- Fontes bibliográficas - Banco de Teses da CAPES; revistas brasileiras da área de Letras e Linguística Aplicada, classificadas como Qualis A1 e A2, com foco em Ensino-Aprendizagem e Formação de Professores; e Google Acadêmico (Scholar Google). Foi analisado, também, o livro intitulado Inglês como Lingua Franca: ensino-aprendizagem e formação de professores, organizado por Gimenez, Calvo e El Kadri (2011);

- Parâmetro Cronológico - período de 2005 a 2012.

Foram feitas basicamente duas leituras para a recuperação dos textos adicionados à pesquisa:

- Leitura de reconhecimento/exploratória: rápida e objetiva, para identificação dos textos relevantes a partir dos títulos, palavraschave, etc.;

- Leitura seletiva: integral, a fim de delimitar o material que realmente interessa, relacionando-o com o objetivo da pesquisa.

O resultado desta etapa se refere a um conjunto de textos que obedecem aos critérios iniciais de inclusão, descritos no protocolo de ações.

O Quadro 1 traz os procedimentos de busca e seleção dos trabalhos, enquanto o Quadro 2 sintetiza as perguntas de pesquisa e procedimentos de análise dos dados: 
Quadro 1 - Procedimentos de busca, total de trabalhos selecionados e nomenclaturas da LI

\begin{tabular}{|c|c|c|c|}
\hline $\begin{array}{c}\text { Ferramentas de } \\
\text { busca }\end{array}$ & Procedimentos & $\begin{array}{c}\text { Trabalhos } \\
\text { encontrados }\end{array}$ & $\begin{array}{c}\text { Trabalhos } \\
\text { selecionados }\end{array}$ \\
\hline $\begin{array}{l}\text { Banco } \\
\text { Dissertações/ } \\
\text { Teses CAPES }\end{array}$ & $\begin{array}{l}\text { - Os termos pesquisados foram } \\
\text { colocados entre aspas (“ ”), para } \\
\text { restrição da temática (ILF); } \\
\text { - Foi selecionada a opção “expressão } \\
\text { exata” para a busca dos textos; } \\
\text { - Os itens pesquisados foram de } \\
2005 \text { a } 2011 \text { (ano mais recente } \\
\text { disponível); } \\
\text { - Foram recuperadas dissertações e } \\
\text { teses para cada ano. }\end{array}$ & 21 & 7 \\
\hline $\begin{array}{l}\text { Google } \\
\text { Acadêmico }\end{array}$ & $\begin{array}{l}\text { - Os termos pesquisados foram } \\
\text { colocados entre aspas (" "), para } \\
\text { restrição da temática (ILF); } \\
\text { - Foi selecionado o item "Pesquisar } \\
\text { na Web"; } \\
\text { - Foram desmarcadas as opções } \\
\text { "incluir patentes" e "incluir citações"; } \\
\text { - Foi selecionado o período de } 2005 \\
\text { a } 2012 \text {. }\end{array}$ & 364 & 41 \\
\hline $\begin{array}{l}\text { Periódicos } \\
\text { nacionais da } \\
\text { área de } \\
\text { Letras/LA }\end{array}$ & $\begin{array}{l}\text { - Foram selecionadas revistas } \\
\text { brasileiras de Letras e Linguística } \\
\text { Aplicada classificadas como Qualis } \\
\text { A1 e A2, com foco em Ensino- } \\
\text { Aprendizagem e Formação de } \\
\text { Professores; } \\
\text { - Assim, temos um total de } 10 \\
\text { periódicos: a) Revista DELTA- } \\
\text { PUC/SP; b) Revista de Estudos da } \\
\text { Linguagem/UFMG; c) Revista } \\
\text { Brasileira de Linguística } \\
\text { Aplicada/UFMG; d) Trabalhos em }\end{array}$ & & \\
\hline
\end{tabular}




\section{Periódicos nacionais da área de Letras/LA}

Linguística Aplicada/UNICAMP; e) Gragoatá/UFF - Universidade Federal Fluminense; f) Revista de Estudos Linguísticos/Veredas/UFJF - Online/Impresso; g) Revista Signum - Estudos da Linguagem/UEL; h) Calidoscópio/UNISINOS; i) Ilha do Desterro/UFSC; j) Linguagem e Ensino, UCPel;

- Os termos pesquisados foram colocados entre aspas (" "), para que a busca se restringisse mais à temática em questão;

- Foi necessária uma busca ano a ano, volume a volume para a seleção dos textos que mais se enquadrassem na temática do ILF, uma vez que a busca pelos termos não gerou resultados satisfatórios. Apenas a Revista Linguagem e Ensino/UCPel gerou resultados na pesquisa pelo termo "inglês como língua franca": 2 textos, dos quais apenas um foi selecionado;

- Não foram consideradas, para a análise, resenhas e notas sobre livros.

\begin{tabular}{|l} 
Livro nacional \\
sobre LF
\end{tabular}

- Foi selecionado também o livro organizado por Gimenez, Calvo e El Kadri (2011), Inglês como Lingua Franca: ensino-aprendizagem e formação de professores

Total de trabalhos selecionados 


\begin{tabular}{|l|l|}
\hline & $\begin{array}{l}\text { As nomenclaturas de LI encontradas nos trabalho são: a) inglês } \\
\text { como língua franca; b) inglês como língua internacional; c) } \\
\text { inglês como língua global; d) World Englishes; e) World }\end{array}$ \\
Nomenclaturas & $\begin{array}{l}\text { English ou inglês como língua mundial; f) língua de fronteira; } \\
\text { da LI }\end{array}$ \\
encontradas nos língua glocal e h) língua multinacional. Algumas \\
trabalhos & $\begin{array}{l}\text { denominações foram encontradas, porém não representaram } \\
\text { objeto de busca. São elas: World Englishes, World English ou } \\
\text { inglês como língua mundial, língua de fronteira e língua glocal. }\end{array}$ \\
\hline
\end{tabular}

Fonte: Bordini (2013)

Quadro 2 - Perguntas de pesquisa e procedimentos de análise dos dados

\begin{tabular}{|l|l|}
\hline \multicolumn{1}{|c|}{ Pergunta } & \multicolumn{1}{c|}{ Procedimentos } \\
\hline $\begin{array}{l}\text { Quais dissertações, teses e artigos } \\
\text { acadêmicos qualificados publicados } \\
\text { no Brasil no período de 2005-2012 } \\
\text { tratam do inglês como língua franca? }\end{array}$ & $\begin{array}{l}\text { Busca de dissertações de mestrado, teses } \\
\text { de doutorado e artigos acadêmicos nas } \\
\text { principais fontes disponíveis na web. }\end{array}$ \\
\hline $\begin{array}{l}\text { Quais os focos dos estudos e quais } \\
\text { entendimentos de ILF são adotados? }\end{array}$ & $\begin{array}{l}\text { Análise dos objetivos e referenciais } \\
\text { teóricos adotados. }\end{array}$ \\
\hline $\begin{array}{l}\text { Qual a natureza dessas pesquisas e } \\
\text { em que contextos foram realizadas? }\end{array}$ & $\begin{array}{l}\text { Análise da seção de metodologia dos } \\
\text { trabalhos, a fim de verificar se incluíram } \\
\text { estudos empíricos, e quem foram os } \\
\text { participantes da pesquisa. }\end{array}$ \\
\hline $\begin{array}{l}\text { Quais implicações pedagógicas } \\
\text { derivam desses estudos? } \\
\text { - resultados }\end{array}$ & $\begin{array}{l}\text { Análise das conclusões dos trabalhos, de } \\
\text { modo a discutir as implicações } \\
\text { pedagógicas. }\end{array}$ \\
\hline
\end{tabular}

Fonte: Bordini (2013)

\section{Estudos sobre ILF}

\subsection{Pesquisas publicadas no Brasil no âmbito do ILF}

No Quadro 3, a seguir, apresentamos as características gerais dos trabalhos, como sua configuração, regiões das publicações de dissertações e teses brasileiras e evolução das produções nacionais. 
Quadro 3 - Características gerais dos trabalhos

\begin{tabular}{|l|l|}
\hline Configuração dos trabalhos & $\begin{array}{l}\text { Artigo (45) > Capítulo de livro (13) }> \\
\text { Dissertações (7) }>\text { Teses (2) }\end{array}$ \\
\hline $\begin{array}{l}\text { Regiões Brasileiras das } \\
\text { Dissertações e Teses }\end{array}$ & Sul (4) > Sudeste (3) > Nordeste (2) \\
\hline $\begin{array}{l}\text { Evolução das pesquisas } \\
\text { nacionais }\end{array}$ & $\begin{array}{l}2011(24)>2010(10)>2012(7)=2005 \\
>2009(6)=2006(6)>2007(4)> \\
2008(3)\end{array}$ \\
\hline
\end{tabular}

Fonte: Bordini (2013)

A concentração da produção acadêmica em formato de artigos pode ser indicativa da adoção recente da terminologia língua franca, global, internacional ou multinacional em nosso país. Dissertações e teses geralmente configuram-se como pesquisas de longo prazo (geralmente de 2 a 4 anos) e, talvez por isso, apareçam em menor número.

Com relação às Instituições de Ensino Superior nas quais foram defendidas as pesquisas recuperadas, temos que a maior parte desses trabalhos (4) foi produzida na Região Sul (UCS, UEL, UEPG e UFRS), enquanto 3 foram realizados na Região Sudeste (2 PUC-RJ e 1 USP) e 2 na Região Nordeste (UFS e UFBA), o que pode ser justificado pelos conteúdos disciplinares dos programas de pós-graduação presentes nessas universidades.

Como se pode observar, houve um crescimento significativo de trabalhos referentes à temática do ILF, entre os anos de 2008 e 2011. O ano de 2011, que coincide com a publicação de obra com título explícito sobre ILF, foi o que exibiu mais trabalhos na área, indício de que o interesse por este campo de pesquisa sob a denominação ILF está se tornando cada vez mais crescente em âmbito nacional.

O Quadro 4 apresenta os temas abordados, juntamente com sua quantificação, no Quadro 5: 
Quadro 4 - Apresentação das categorias temáticas dos trabalhos nacionais

\begin{tabular}{|c|c|}
\hline Tema & Apresentação \\
\hline $\begin{array}{l}\text { Crenças e Atitudes de } \\
\text { estudantes de Letras }\end{array}$ & $\begin{array}{l}\text { Crenças e Atitudes de estudantes de Letras } \\
\text { (atitudes e opiniões de } 24 \text { graduandos brasileiros de } \\
\text { Letras sobre a LI no mundo; representações de } \\
\text { alunas-professoras do } 4^{\circ} \text { ano de um curso de Letras } \\
\text { da UEL, sobre o estatuto do ILF; reflexões do } 1^{\circ} \text { e } \\
\text { do último ano de duas instituições de ensino acerca } \\
\text { do ensino de ILI). }\end{array}$ \\
\hline $\begin{array}{l}\text { Crenças e atitudes de } \\
\text { estudantes de Letras e } \\
\text { professores da rede } \\
\text { pública }\end{array}$ & $\begin{array}{l}\text { Reflexão sobre algumas representações em torno } \\
\text { do falante nativo e não nativo de inglês, para } \\
\text { compreender as práticas discursivas de um } \\
\text { professor de inglês e de seus alunos. }\end{array}$ \\
\hline $\begin{array}{l}\text { Crenças e Atitudes de } \\
\text { formadores de professores }\end{array}$ & $\begin{array}{l}\text { Investigar as atitudes de formadores de professores } \\
\text { em relação ao estatuto de ILF. }\end{array}$ \\
\hline $\begin{array}{l}\text { Crenças e atitudes de } \\
\text { professores de inglês do } \\
\text { setor público }\end{array}$ & $\begin{array}{l}\text { Entrevista com cinco professoras e três professores } \\
\text { de língua inglesa que atuam nos Ensinos Médio e } \\
\text { Fundamental em duas escolas municipais de Belo } \\
\text { Horizonte - uma central e outra periférica, sobre o } \\
\text { estatuto do ILF; Revisão sobre Inglês Internacional, } \\
\text { nativo e não nativos de inglês, materiais de ensino, } \\
\text { professor de inglês e futuro da LI; Questionário } \\
\text { aberto com } 42 \text { situações-problema aplicado a alunos } \\
\text { (29) do } 4^{\circ} \text { ano de Letras de uma universidade de } \\
\text { Londrina, Paraná; questionário/entrevista } \\
\text { semiestruturada com professores formadores (6) do } \\
\text { referido curso; Trazer discussões acerca da literatura } \\
\text { de pesquisa (ILF), tomando como base o ponto de } \\
\text { vista de um professor. }\end{array}$ \\
\hline $\begin{array}{l}\text { Crenças e atitudes de } \\
\text { estudantes; Crenças e } \\
\text { atitudes de profissionais }\end{array}$ & $\begin{array}{l}\text { Dez estudantes e profissionais chineses de diversas } \\
\text { áreas (quatro deles são vendedores, dois trabalham } \\
\text { na área de marketing, dois são professores, um } \\
\text { estudante e um que trabalha com negócios } \\
\text { internacionais. Cinco com graduação na área de } \\
\text { línguas estrangeiras (sendo que quatro } \\
\text { especificamente na área de inglês), dois com } \\
\text { graduação em Economia, dois em Comércio } \\
\text { Exterior e um em Administração) acerca do status } \\
\text { da língua inglesa como língua franca. }\end{array}$ \\
\hline Currículo de LI & $\begin{array}{l}\text { Estudo comparativo entre dois documentos } \\
\text { curriculares: OCEM-LE (âmbito nacional) e a } \\
\text { Proposta Curricular do Estado de SP - Inglês; }\end{array}$ \\
\hline
\end{tabular}




\begin{tabular}{|c|c|}
\hline Currículo de LI & $\begin{array}{l}\text { Corpus - Os programas das disciplinas do } \\
\text { curso de Letras (fonte documental do tipo } \\
\text { oficial primária - documentos oficiais da } \\
\text { instituição). }\end{array}$ \\
\hline Discussão conceitual & $\begin{array}{l}\text { Nomenclaturas da LI; Relato da situação do } \\
\text { inglês no mundo; Reflexões sobre o inglês, } \\
\text { globalização e educação linguística; a } \\
\text { geopolítica da difusão do inglês no mundo; } \\
\text { Reflexão a respeito do processo de } \\
\text { ensino-aprendizagem de LI como idioma } \\
\text { global, e do papel do profissional docente; } \\
\text { Discussão sobre a LI no mundo e descrição } \\
\text { das propriedades de uma língua internacional; } \\
\text { Imposição de cultura e legitimidade; Estudo } \\
\text { dos mecanismos de adaptação da LI a novas } \\
\text { realidades; Esclarecer o significado da } \\
\text { expressão World English; Revisão sobre a } \\
\text { história da expansão do inglês, ILF e } \\
\text { variedades da LI; Análise sobre o caminho } \\
\text { percorrido pelo inglês; Panorama histórico da } \\
\text { expansão da LI no mundo. }\end{array}$ \\
\hline $\begin{array}{l}\text { Discussão da língua } \\
\text { inglesa no contexto da } \\
\text { globalização }\end{array}$ & $\begin{array}{l}\text { Discussão da mundialização do inglês no } \\
\text { contexto da globalização; Leituras sobre o } \\
\text { fenômeno "globalização"; Compreensão sobre } \\
\text { como a LI passou a ser conhecida como língua } \\
\text { franca global. }\end{array}$ \\
\hline $\begin{array}{l}\text { Ferramentas } \\
\text { tecnológicas } \\
\text { no ensino de Inglês }\end{array}$ & $\begin{array}{l}\text { Aplicação das NTICs (Novas Tecnologias de } \\
\text { Informação e Comunicação) no ensino de } \\
\text { inglês; Identificação de ações de aprendizagem } \\
\text { por nativo digitais (jogos computacionais da } \\
\text { internet). }\end{array}$ \\
\hline $\begin{array}{l}\text { Formação inicial de } \\
\text { professores }\end{array}$ & $\begin{array}{l}\text { Reflexão sobre a formação do professor de } \\
\text { inglês na era das Tecnologias de Comunicação } \\
\text { Digital. }\end{array}$ \\
\hline ILF e identidade & $\begin{array}{l}\text { Percepção do professor e alunos sobre sua } \\
\text { identidade no contexto do ILF; formação da } \\
\text { identidade do aprendiz de LI. }\end{array}$ \\
\hline
\end{tabular}




\begin{tabular}{|c|c|}
\hline Inteligibilidade & $\begin{array}{l}\text { Discussão sobre LF e inteligibilidade; } \\
\text { Discussão sobre questões fonológicas d LI, } \\
\text { considerando o Inglês para Aviação; Foco na } \\
\text { pronúncia de graduandos brasileiros de ILE; } \\
\text { Investigação de aspectos impeditivos da } \\
\text { comunicação entre falantes brasileiros/ } \\
\text { franceses de LI; Teste da eficácia do LFC } \\
\text { proposto por Jenkins (2000); Verificar de a } \\
\text { inserção de vogais na fala de aprendizes } \\
\text { brasileiros de LI pode afetar a inteligibilidade. }\end{array}$ \\
\hline Materiais didáticos & $\begin{array}{l}\text { Análise de duas coleções de livros didáticos de } \\
\text { inglês do ensino médio; análise de livro } \\
\text { didático com a finalidade de verificar se este } \\
\text { está incorporando a questão das variedades } \\
\text { linguísticas; Análise de LD com foco em } \\
\text { aspectos culturais. }\end{array}$ \\
\hline Questões pragmáticas & $\begin{array}{l}\text { Investigação dos esforços de participantes na } \\
\text { obtenção de sucesso nas comunicações em LI } \\
\text { Análise da competência de funcionários de } \\
\text { duas empresas comerciais (município de } \\
\text { Medianeira, Paraná). }\end{array}$ \\
\hline $\begin{array}{l}\text { Reflexões sobre o } \\
\text { ensino de inglês no } \\
\text { contexto de ILF }\end{array}$ & $\begin{array}{l}\text { Discussão sobre ensino de pronúncia de LI na } \\
\text { era da língua franca; Percurso histórico de } \\
\text { métodos/abordagens para o ensino de LI; } \\
\text { Opinião de professores acerca do NLF; } \\
\text { reflexões sobre ensino-aprendizagem pela } \\
\text { perspectiva do ILF; Análise da expansão da LI } \\
\text { no mundo e o consequente interesse pelo seu } \\
\text { aprendizado; Discussão do papel do professor } \\
\text { de LI nos dias atuais; Discussão da } \\
\text { importância das narrativas literárias no ensino } \\
\text { de LI; Análise de aspectos do ILI; Discussão } \\
\text { da necessidade de reformulação do } \\
\text { componente cultural no ensino/aprendizagem } \\
\text { de línguas; Discussão de alguns aspectos } \\
\text { pertinentes ao estatuto do ILF (língua, cultura } \\
\text { e identidade); Percepção do professor de } \\
\text { inglês de diversos contextos educacionais }\end{array}$ \\
\hline
\end{tabular}


Reflexões sobre o ensino de inglês no contexto de ILF

Revisão bibliográfica de estudos sobre sua atuação no contexto do ILI, defendendo uma pedagogia intercultural crítica; Representação da LI no contexto global/nacional; Implicações do ILI para a sala de aula; Reflexão da LI por meio das perpectivas críticas;

Contraste entre o paradigma de ensino pautado no ILE x ILI.

Mapeamento de estudos brasileiros sobre o ILF

Fonte: Bordini (2013)

Quadro 5 - Quantificação dos trabalhos mapeados

\begin{tabular}{|c|c|c|}
\hline Tema & Autores & $\begin{array}{c}\text { Qtde } \\
\text { Trabalhos }\end{array}$ \\
\hline $\begin{array}{l}\text { Crenças e Atitudes de } \\
\text { estudantes de Letras }\end{array}$ & $\begin{array}{l}\text { BERTO (2011); SOUZA, BARCARO; } \\
\text { GRANDE (2011); MOTT- } \\
\text { FERNANDEZ; FOGAÇA (2009) }\end{array}$ & 3 \\
\hline $\begin{array}{l}\text { Crenças e atitudes de } \\
\text { estudantes de Letras e } \\
\text { professores da rede } \\
\text { pública }\end{array}$ & FIGUEREDO (2011) & 1 \\
\hline $\begin{array}{l}\text { Crenças e Atitudes de } \\
\text { formadores de } \\
\text { professores }\end{array}$ & EL KADRI (2011) & 1 \\
\hline $\begin{array}{l}\text { Crenças e atitudes de } \\
\text { professores de inglês do } \\
\text { setor público }\end{array}$ & $\begin{array}{l}\text { ZACCHI (2006); NUNES (2006); EL } \\
\text { KADRI (2010a); UR (2010) }\end{array}$ & 4 \\
\hline $\begin{array}{l}\text { Crenças e atitudes de } \\
\text { estudantes; Crenças e } \\
\text { atitudes de profissionais }\end{array}$ & CALVO et al. (2009) & 1 \\
\hline Currículo de LI & DUBOC (2011); EL KADRI (2010b) & 2 \\
\hline Discussão conceitual & $\begin{array}{l}\text { LONGARAY; LIMA (2010); DAVID } \\
\text { (2005); MOITA LOPES (2005); } \\
\text { LACOSTE (2005); BERGER (2010); } \\
\text { LEFFA (2006); SANTOS (2007); } \\
\text { SKYBINA (2006); }\end{array}$ & 13 \\
\hline
\end{tabular}




\begin{tabular}{|c|c|c|}
\hline Discussão conceitual & $\begin{array}{l}\text { RAJAGOPALAN (2011); SILVA, H. } \\
\text { M. (2009); BARROS (2005); SCHÜTZ } \\
\text { (2005); BERNS et al. (2011) }\end{array}$ & 13 \\
\hline $\begin{array}{l}\text { Discussão da língua } \\
\text { inglesa no contexto da } \\
\text { globalização }\end{array}$ & $\begin{array}{l}\text { MESQUITA; MELLO (2007); ASSIS- } \\
\text { PETERSON; COX (2007); MOITA } \\
\text { LOPES (2008) }\end{array}$ & 3 \\
\hline $\begin{array}{l}\text { Ferramentas tecnológicas } \\
\text { no ensino de Inglês }\end{array}$ & $\begin{array}{l}\text { BERGER (2005, 2007); PESCADOR } \\
(2010)\end{array}$ & 3 \\
\hline $\begin{array}{l}\text { Formação inicial de } \\
\text { professores }\end{array}$ & MOTTER; CATAPAN (2011) & 1 \\
\hline ILF e identidade & $\begin{array}{l}\text { KALVA; FERREIRA (2011); KALVA } \\
\text { (2012) }\end{array}$ & 2 \\
\hline Inteligibilidade & $\begin{array}{l}\text { BECKER (2009, 2011); SILVEIRO } \\
\text { (2012); CRUZ; PEREIRA (2006); } \\
\text { REIS; CRUZ (2010); CRUZ (2006, } \\
\text { 2008) }\end{array}$ & 7 \\
\hline Materiais didáticos & $\begin{array}{l}\text { SILVA, V. E. S. (2011); SILVA, E. R. } \\
\text { (2011); SILVA, J. M. (2012) }\end{array}$ & 3 \\
\hline Questões pragmáticas & $\begin{array}{l}\text { DE PAOLA (2010); MENONCIN; } \\
\text { VON BORSTEL (2012) }\end{array}$ & 2 \\
\hline $\begin{array}{l}\text { Reflexões sobre o ensino } \\
\text { de inglês no contexto de } \\
\text { ILF }\end{array}$ & $\begin{array}{l}\text { GOMES (2010); BARBOSA (2011); } \\
\text { DUTRA; COSTA (2011); SCHMITZ } \\
\text { (2012), FORTES; SALEM (2011); } \\
\text { SIQUEIRA (2005); FESTINO (2011); } \\
\text { GONÇALVES; MOTTER (2012), } \\
\text { SALOMÃO (2011); PEDERSON } \\
\text { (2011); SIQUEIRA (2008, 2011); } \\
\text { COSTA; GIMENEZ (2011); } \\
\text { JORDÃO (2011); ROCHA; SILVA } \\
\text { (2011); SALLES; GIMENEZ (2010); } \\
\text { RAJAGOPALAN (2009); } \\
\text { LONGARAY (2009); SHOEMAKER } \\
\text { (2011); SIQUEIRA; ANJOS (2012) }\end{array}$ & 20 \\
\hline $\begin{array}{l}\text { Revisão bibliográfica de } \\
\text { estudos }\end{array}$ & CALVO; EL KADRI (2011) & 1 \\
\hline
\end{tabular}

Fonte: Bordini (2013) 
Do total de 67 trabalhos analisados, $41^{10}$ se configuram como ensaísticos, com foco em reflexões do(s) autor(es), enquanto 26 se caracterizaram como empíricos. Isto pode explicar a grande concentração na categoria "Reflexões sobre o ensino de inglês no contexto de ILF". Assim, uma possível lacuna, portanto, é a de trabalhos investigando as características de interações envolvendo brasileiros e falantes de outras línguas. Esses seriam dados que poderiam compor acervos como o do VOICE, por exemplo, permitindo que pesquisadores busquem regularidades, de modo a subsidiar professores.

A sequência dos termos que apareceram em todos os trabalhos é resumida da seguinte forma: ILF (37) > ILI (23) > ILG (14) > "WE" ou inglês como língua mundial $(13)>$ WEs ou World Englishes (6) $>$ Língua glocal (2) > Língua de fronteira (1) > Língua multinacional (1). Embora haja diversidade terminológica, é possível afirmar que, no geral, o sentido conferido à LI em tempos de globalização é similar, ou seja, o entendimento dos autores se assemelha. A língua inglesa - seja ela compreendida como uma língua franca global, língua internacional, língua global, língua mundial, enfim, "língua glocal" - traz os sentidos de comunicação internacional da língua, principalmente devido ao número de falantes não nativos ter ultrapassado o número de falantes nativos, fator que provoca um desequilíbrio quantitativo no uso do inglês. Deste modo, vemos que a língua inglesa vem sendo entendida tal como a define Seidlhofer (2011, p. 7), definição esta apresentada na seção 1 (cf. nota 6).

As conclusões dos estudos, em sua maioria, tratam da formação do professor como aspecto central do ILF a ser encarado com seriedade, a fim de formar cidadãos conscientes de si e críticos do mundo em que vivem. As vozes dos professores se fazem importantes na tomada de consciência sobre as variedades de inglês existentes (UR, 2010) e, portanto, um investimento maciço na formação inicial/continuada de professores precisa ser realizado

${ }^{10}$ As categorias temáticas que abarcam estes trabalhos são: a) Crenças e atitudes de professores do setor público (2); b) Discussão Conceitual (12); c) Discussão da língua inglesa no contexto da globalização (3); d) Ferramentas tecnológicas no ensino de inglês (3); e) Formação inicial de professores (1); f) Inteligibilidade (2); g) Reflexões sobre o ensino de inglês no contexto de ILF (17); e h) Revisão bibliográfica de estudos (1). Vale frisar que as categorias a, b, d, f, g também enquadraram pesquisas empíricas. 
para que a escola pública seja um palco de mudanças (SIQUEIRA; ANJOS, 2012). Os objetivos de ensino de LI precisariam ser reconfigurados para alcançar uma pedagogia apropriada (PEDERSON, 2011), assumindo seu caráter local (SIQUEIRA, 2008). A expansão da LI precisa ser tratada de maneira crítica e são necessários espaços para tal debate (BERTO, 2011; CALVO; EL KADRI, 2011; SOUZA; BARCARO; GRANDE, 2011; JORDÃO, 2011), principalmente entre os profissionais, tanto na formação inicial quanto na continuada.

Com relação ao ensino, Rocha e Silva (2011) afirmam que é importante desenvolvermos um olhar múltiplo e polifônico de compreender o inglês na contemporaneidade e seu ensino poderia adotar uma postura bilíngue glocal, ou seja, tanto universal quanto particular, com o intuito de atender às necessidades dos aprendizes. Para tanto, o ensino deveria ser atrativo e de qualidade, visando principalmente a suprir a deficiência do sistema escolar público (ASSIS-PETERSON; COX, 2007), buscando a negociação entre a vida local e os designs globais por meio da LI, também conhecida como língua de fronteira (MOITA LOPES, 2008), ou ainda "World English", um fenômeno inacabado, dotado de hibridismo e pertencente a todos que o utilizam (RAJAGOPALAN, 2009, 2011).

A internet poderia se configurar como uma ferramenta útil ao ensino de LI, a fim de formar o cidadão para o mercado de trabalho (BERGER, 2005), uma vez que, ao ser adequadamente empregada, funciona como facilitador do processo de ensino-aprendizagem.

No que tange ao currículo, Berns et al. (2011) afirmam que existe a necessidade de inclusão das variedades múltiplas da LI nos currículos das escolas ou instituições de ensino superior brasileiras. Além disso, El Kadri (2010b) afirma que a maioria dos programas das disciplinas do curso de Letras analisados não problematizava esta questão, embora iniciassem ações pontuais para tratar do ILF. Para Duboc (2011), orientações curriculares, sejam estaduais ou nacionais, precisam ter um caráter orientador, para que o professor tenha uma visão mais ampla e compreenda de que maneira ele pode inserir o global no local, e vice-versa. Segundo a autora, essas orientações curriculares poderiam contemplar o estatuto do inglês como língua franca no mundo.

Com relação a estudos sobre inteligibilidade, a "familiaridade" é vista como um fator decisivo entre ouvinte/falante. Reis e Cruz (2010) argumentam que o professor é responsável por tomar conhecimento de aspectos de 
pronúncia que interferem na compreensão de interlocutores, além de estabelecer critérios de avaliação de pronúncia.

No que diz respeito a materiais didáticos, Silva, E. R. (2011) e Silva, J. M. (2012) apontam a falta de exemplos referentes aos ingleses do mundo, bem como referências culturais específicas nos livros didáticos analisados, e recomendam alterações a fim de se adequarem à realidade global e local.

Os trabalhos foram agrupados em 16 categorias para fins analíticos, como podemos observar nos quadros 4 e 5, e os conceitos de ILF mostraram-se, em sua maioria, convergentes na questão semântica. O termo ILF (inglês como língua franca), foi o mais utilizado, seguido dos termos "inglês como língua internacional", "inglês como língua global", "inglês como língua mundial" ou "World English", "World Englishes (WEs)" e "língua glocal” (KALVA; FERREIRA, 2011) em ordem decrescente. Outros 2 termos foram utilizados na mesma proporção (1:1): f) língua de fronteira (MOITA LOPES, 2008) e língua multinacional (LEFFA, 2002), contando apenas com um trabalho para cada termo. Acreditamos que isto se deve, principalmente, à quantidade de trabalhos encontrados na busca pelos referidos termos (seção metodológica). Somente no Google Acadêmico ${ }^{11}$ foram recuperados 22 trabalhos, quando selecionada a palavra-chave "inglês como língua franca", demonstrando um grau significativo de aceitação do termo.

Com relação à natureza e contextos das pesquisas, é possível observar que a maioria dos trabalhos é de cunho reflexivo, logo, o número de estudos empíricos se faz menor, fator que corrobora a citação de Jenkins, Cogo e Dewey (2011, p. 285): “[...] Mesmo os poucos pesquisadores da região que se empenham sobre o ILF tendem a focar em questões mais amplas, ao invés de locais". Estes trabalhos, em sua maioria, realizam uma discussão da LI junto ao processo de globalização. São poucos os trabalhos que realmente se preocupam com as questões locais ou, quando muito, defendem o falante não nativo como legítimo (FIGUEREDO, 2011). Mas, e o falante brasileiro de inglês? Como ele se vê dentro do complexo engendrado pelo ILF? Acreditamos que sejam necessárias mais pesquisas com o propósito de mapear o perfil do falante brasileiro de outras áreas. Logicamente, essa pesquisa se configurará como "localmente situada", uma vez que não é possível traçar um único perfil brasileiro de fala.

${ }^{11}$ Disponível em: < http://scholar.google.com.br/schhp?hl=pt-BR>. 
O Gráfico 1, a seguir, traz o contexto/informantes da pesquisa. Compreensivelmente, nota-se o predomínio de estudos com profissionais da área de Inglês, demonstrando que, em nosso país, a recepção ao ILF tem se dado sob um enquadre de preocupações pedagógicas.

Gráfico 1 - Informantes das pesquisas empíricas mapeadas (26)

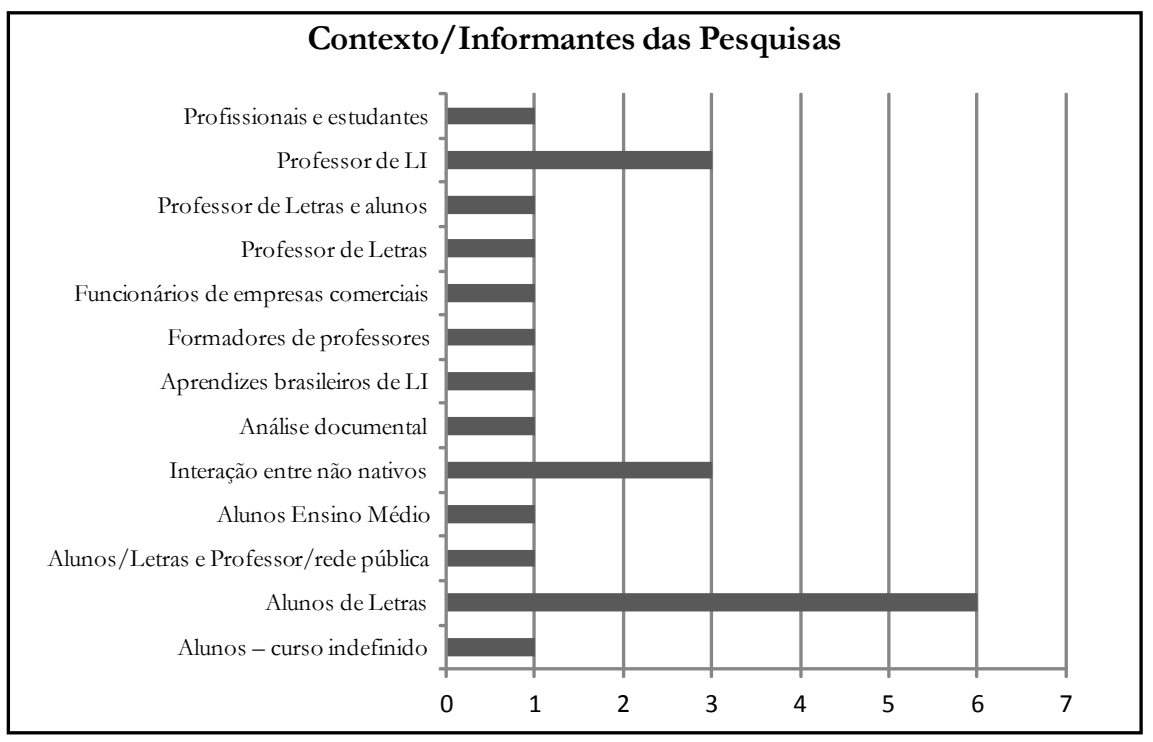

Fonte: Bordini (2013)

O foco maior dos trabalhos se deu com alunos de Letras e, logo a seguir, o professor. Acreditamos que as pesquisas com professores se fazem tão importantes quanto com alunos, uma vez que os primeiros são responsáveis pela desenvoltura dos últimos, no que tange à proficiência linguística, os entendimentos sobre a LI no mundo globalizado, juntamente às questões linguísticas relacionadas à LI, ou ILF, ou ILI, ou língua mundial, ou língua global, ou língua de fronteira, enfim, os termos parecem infinitos!

No que concerne às implicações pedagógicas, a maioria das pesquisas aponta para a formação continuada de professores de LI como a saída para a miscelânea ideológia/cultural/identitária trazida pelo inglês para o mundo contemporâneo. Zacchi (2006), por exemplo, como resultado de sua pesquisa, afirma que os professores navegam entre discursos hegemônicos (inglês como 
língua neutra, livre de conotações políticas) e contra-hegemônicos (forma de resistência à ideologia dominante). Isto implica, por exemplo, no fato de que seus alunos poderão levar consigo os mesmos discursos, ao invés de defenderem uma única posição. Logo, o campo da formação de professores deve se fazer cada vez mais presente, a fim de qualificar profissionais críticos para atuarem no mercado de trabalho, e que não definam a LI apenas como a língua "da moda", mas como uma ferramenta útil ao ensino-apendizagem, ao empoderamento dos aprendizes (BARBOSA, 2010/2011).

\section{Considerações Finais}

Essa pesquisa procurou compreender a recepção das questões atinentes ao ILF que repercutiram na produção acadêmica brasileira no período de 2005 a 2012. Ainda são escassos os trabalhos empíricos na área de ILF, especialmente os que investiguem interações envolvendo brasileiros e falantes de outras línguas. Nesse sentido, seria desejável que mais estudos se dedicassem a documentar interações envolvendo brasileiros, contribuindo com a literatura internacional, que vem acumulando evidências das características frequentes de uso do inglês entre falantes de diferentes línguas maternas.

Exemplos do inglês utilizado no mundo em contraste com o inglês utilizado por falantes brasileiros poderiam começar a fazer parte da agenda de pesquisa dos pesquisadores de nossa área. Destacamos, porém, pesquisas como as de Cruz (2006, 2008), Cruz e Pereira (2006) e Reis e Cruz (2010), que abordaram questões de inteligibilidade no cenário brasileiro, corroborando a ampliação especialmente no campo fonológico da LI, falada por brasileiros, incluindo suas facilidades/dificuldades ao se expressarem nesta língua.

O levantamento aqui tratado nos permite identificar um crescente interesse de pesquisadores brasileiros sobre ILF. De modo geral, apresentamos textos que se debruçam sobre confusões terminológicas, conceitos e (des)entendimentos sobre o que vem a ser ILF. Em um primeiro momento, portanto, parece que estamos ainda tentando elaborar os sentidos da língua inglesa em nosso país, para derivarmos implicações para seu ensino. As preocupações pedagógicas, refletidas na preferência por estudos com alunos e professores de Inglês, são pertinentes e tomam como foco a questão de qual inglês queremos aprender e para quê. Os autores identificados procuram ampliar a compreensão do inglês como língua de falantes nativos dos Estados Unidos ou da Inglaterra, para a língua usada em múltiplos contextos com 
propósitos diversos. Essa diversidade requer, naturalmente, uma educação sensível a caracterizações mais recentes de uso da língua.

Parece haver acúmulo suficiente para a constituição de uma agenda brasileira de estudos sobre ILF, de modo a problematizar seus sentidos e suas possibilidades de apropriação pedagógica em diferentes contextos de ensino-aprendizagem.

\section{Referências}

ASSIS-PETERSON, A. A.; COX, M. I. P. Inglês em tempos de globalização: para além de bem e mal. Calidoscópio, São Leopoldo, v. 5, n. 1, p. 5-14, jan./abr. 2007.

BARBOSA, J. R. A. Nem britânico, nem americano: o ensino da pronúncia do inglês como língua internacional. Revista de Letras, São Paulo, v. 30, n. 1/ 4, p. 82-92, jan. 2010/dez. 2011.

BARROS, C. D. B. R. O inglês, língua global dos dias atuais. 2005. Dissertação (Mestrado em Letras) - Pontifícia Universidade Católica do Rio de Janeiro, Rio de Janeiro.

BECKER, M. R. ELF: inglês como língua franca. Eletras, Curitiba, v. 19, n. 19, p. 1-10, dez. 2009.

BECKER, M. R. A questão da inteligibilidade do inglês como língua franca. In: CONGRESSO INTERNACIONAL DA ABRALIN, 7., 2011, Curitiba. Anais... Curitiba: UFPR, 2011. p. 2789-2801.

BERGER, M. A. F. O papel da língua inglesa no contexto de globalização e as implicações do uso das NTICs no processo de ensino/ aprendizagem desse idioma. 2005. Dissertação (Mestrado em Educação) - Universidade Federal de Sergipe, São Cristóvão.

BERGER, M. A. F. A globalização da economia, a internet, e o ensino de língua inglesa como idioma global. Revista da Fapese, Aracaju, v. 3, n. 1, p. 37-56, jan./jun. 2007. 
BERGER, M. A. F. A língua inglesa, globalização e o processo de formação do profissional docente. Cadernos de Pesquisa e Extensão Desafios Críticos-CPEDeC, Aracaju, v. 5, n. 5, p. 119-125, jan./jun. 2010.

BERNS, M. Perspectives on English as a lingua franca. In: HOFFMAN, T.; SIEBERS, L. (Eds.). World Englishes: problems, properties and prospects. Amsterdam: John Benjamins, 2009. p. 369-384.

BERNS, M. English as a lingua franca: a conversation with Margie Berns. In: GIMENEZ, T.; CALVO, L. C. S.; EL KADRI, M. S. (Orgs.). Inglês como lingua franca: ensino-aprendizagem e formação de professores. Campinas: Pontes, 2011. p. 293-303.

BERTO, P. L. English language teaching in Brazil: pursuing a pluricentric approach. In: GIMENEZ, T.; CALVO, L. C. S.; EL KADRI, M. S. (Orgs.). Inglês como lingua franca: ensino-aprendizagem e formação de professores. Campinas: Pontes, 2011. p. 139-161.

BORDINI, M. Estudos sobre inglês como língua franca no contexto brasileiro (2005-2012). 2013. Dissertação (Mestrado em Estudos da Linguagem) Universidade Estadual de Londrina, Londrina.

CALVO, L. C. S.; EL KADRI, M. S. Mapeamento de estudos nacionais sobre Inglês como Língua Franca. In: GIMENEZ, T.; CALVO, L. C. S.; EL KADRI, M. S. (Orgs.). Inglês como língua franca: ensino-aprendizagem e formação de professores. Campinas: Pontes, 2011. p. 17-44.

CALVO, L. C. S.; RIOS-REGISTRO, E. S.; OHUSHI, M. C. G.; EL KADRI, M. S. Percepções de estudantes e profissionais chineses sobre o status do inglês como língua franca. Revista X, Curitiba, v. 2, n. 0, p. 1-21, 2009.

COSTA, G. J. M. M.; GIMENEZ, T. Lady Gaga vai à aldeia Kaingang. . In: GIMENEZ, T.; CALVO, L. C. S.; EL KADRI, M. S. (Orgs.). Inglês como língua franca: ensino-aprendizagem e formação de professores.

Campinas: Pontes, 2011. p. 117-135

CRUZ, N. C. Inteligibilidade de pronúncia no contexto de inglês como língua internacional. Intercâmbio, São Paulo, v. 15, p. 1-11, 2006. 
CRUZ, N. C. Vowel insertion in the speech of Brazilian learners of English: a source of unintelligibility? Ilha do Desterro, Florianópolis, v. 2, n. 55, p. 133-152, jul./dez. 2008.

CRUZ, N. C.; PEREIRA, M. A. Pronúncia de aprendizes brasileiros de inglês e inteligibilidade: um estudo com dois grupos de ouvintes. Revista Virtual de Estudos da Linguagem - REVEL, v. 4, n. 7, p. 1-26, ago. 2006.

DAVID, P. D. O inglês no mundo: língua de prestígio. Revista Trama, Rio de Janeiro, v. 1, n. 2, p. 209-215, jul./dez. 2005.

DE PAOLA, A. L. O. Encontros de serviço em contextos do uso de inglês como lingua franca: sobreposições como estratégias de solidariedade. 2010. Dissertação (Mestrado em Letras) - Pontifícia Universidade Católica do Rio de Janeiro, Rio de Janeiro.

DEWEY, M.; JENKINS, J. English as a lingua franca in the global context: interconnectedness, variation and change. In: SAXENA, M.; OMONIYI, T. (Orgs.). Contending with globalization in world englishes. Bristol: Multilingual Matters, 2010. p. 72-92.

DUBOC, A. P. M. Redesenhando currículos de língua inglesa em tempos globais. RBLA, Belo Horizonte, v. 11, n. 3, p. 727-745, 2011.

DUTRA, C. C.; COSTA, A. A pronúncia do inglês como língua franca e o respeito à identidade linguística. In: SEMINÁRIO DE PÓS-

GRADUAÇÃO, 2011, Novo Hamburgo, RS. Anais... Novo Hamburgo: Universidade Feevale, 2011. p. 60-66.

EL KADRI, M. S. Atitudes sobre o estatuto do inglês como língua franca em curso de formação inicial de professores. 2010a. Dissertação (Mestrado em Estudos da Linguagem) - Universidade Estadual de Londrina, Londrina.

EL KADRI, M. S. Inglês como língua franca: um olhar sobre programas disciplinares de um curso de formação inicial de professores de inglês. Entretextos, Londrina, v. 10, n. 2, p. 64-91, 2010b.

EL KADRI, M. S. Inglês como língua franca: atitudes de formadores de professores. In: GIMENEZ, T.; CALVO, L. C. S.; EL KADRI, M. S. (Orgs.). Inglês como língua franca: ensino-aprendizagem e formação de professores. Campinas: Pontes, 2011. p. 163-192. 
EL KADRI, M. S.; GAMERO, R.; GIMENEZ, T. Material didático para a educação tecnológica de professores de inglês: uma experiência no âmbito do programa 'novos talentos'. Linguagem e Ensino, v. 1 5, n.1, p. 181 212, jan./jun. 2012.

ERLING, E. J. The many names of English: a discussion of the variety of labels given to the language in its worldwide role. English Today, Cambridge, v. 21, n. 1, p. 40-44, Jan. 2005.

FERGUSON, G. Issues in researching English as a lingua franca: a conceptual enquiry. International Journal of Applied Linguistics, Oslo, v. 19, n. 2, p. 117-135, Jul. 2009.

FESTINO, C. G. The importance of the literary text in the teaching of English as an international language. Todas as Letras Q, São Paulo, v. 13, n. 1, p. 54-62, 2011.

FIGUEREDO, C. J. O falante nativo de inglês versus o falante não-nativo: representações e percepções em uma sala de aula de inglês. Linguagem \& Ensino, Pelotas, v. 14, n. 1, p. 67-92, jan./jun. 2011.

FIRTH, A. The lingua franca factor. Intercultural Pragmatics, v. 6, n. 2, p. 147$170,2009$.

FORTES, R. A.; SALEM, M. M. The "englishes": an approach of the learning of English language as a global language. Trivium, Pitanga, v. 2, n. 1, p. 93-100, jan./jun. 2011.

FRIEDRICH, P.; BERNS, M. Introduction: english in South America, the forgotten continent. World Englishes, Oxford, v. 22, n. 2, p. 83-90, May 2003.

GIMENEZ, T.; CALVO, L. C. S.; EL KADRI, M. S. (Orgs.). Inglês como língua franca: ensino-aprendizagem e formação de professores. Campinas: Pontes, 2011.

GIMENEZ, T.; CALVO, L. C. S.; EL KADRI, M. S. English as a lingua franca: a Brazilian perspective. In: BAYYURT, Y.; AKCAN, S. (Orgs.). ELF5. In: INTERNATIONAL CONFERENCE OF ENGLISH AS A LINGUA FRANCA 5, 2013, Istanbul. Proceedings... Istanbul: Bogazici University, 2013. p. 241-248. 
GOMES, M. L. C. Uma reflexão sobre o inglês como língua franca e os novos rumos para o ensino de pronúncia com a linguística probabilística. In: ENCONTRO DO CELSUL, 9., 2010, Palhoça. Anais... Palhoça: Universidade do Sul de Santa Catarina, out. 2010. p. 1-10.

GONÇALVES, A. R.; MOT'TER, R. M. B. Sobre o ensino de língua inglesa no contexto global: língua franca, hibridismo linguístico e homogeneização cultural. E-scrita - Revista do Curso de Letras da Uniabeu, Nilópolis, v. 3, n. 3A, p. 1-14, set./dez. 2012.

JENKINS, J. The phonology of English as an international language. Oxford: Oxford University Press, 2000.

JENKINS, J. Current perspectives on teaching world English and English as a lingua franca. TESOL Quarterly, Washington, v. 40, n. 1, p. 157-181, Mar. 2006.

JENKINS, J; COGO, A.; DEWEY, M. State-of-the-art article: review of developments in research into English as a lingua franca. Language Teaching, Cambridge, v. 44, n. 3, p. 281-315, Jul. 2011.

JORDÃO, C. M. A posição do inglês como língua internacional e suas implicações para a sala de aula. In: GIMENEZ, T.; CALVO, L. C. S.; EL KADRI, M. S. (Orgs.). Inglês como língua franca: ensino-aprendizagem e formação de professores. Campinas: Pontes, 2011. p. 221-252.

KACHRU, B. B. Standards, codification and sociolinguistic realism: the English language in the outer circle. In: QUIRK, R.; WIDDOWSON, H. (Eds.). English in the world: teaching and learning the language and literatures. Cambridge: Cambridge University Press, 1985. p. 11-30.

KALVA, J. M. Identidade nacional e língua franca: negociações no processo de ensino e aprendizagem de inglês. 2012. Dissertação (Mestrado em Linguagem, Identidade e Subjetividade) - Universidade Estadual de Ponta Grossa, Ponta Grossa.

KALVA, J. M.; FERREIRA, A. J. Inglês como língua franca e a concepção de identidade nacional por parte do professor de inglês: uma questão de formação. Fórum Linguístico, Florianópolis, v. 8, n. 2, p. 165-176, jul./dez. 2011. 
LACOSTE, Y. Por uma abordagem geopolítica da difusão do inglês. In: LACOSTE, Y.; RAJAGOPALAN, K. (Org.). A geopolitica do inglês. São Paulo: Parábola, 2005. p. 7-11.

LEFFA, V. Teaching English as a multinational language. The Linguistic Association of Korea Journal, Seul, v. 10, n. 1, p. 29-53, 2002.

LEFFA, V. Língua estrangeira hegemônica e solidariedade internacional. In: KARWOSKI, A. M.; BONI, V. F. C. V. (Orgs.). Tendências contemporâneas no ensino de inglês. União da Vitória: Kaygangue, 2006. p. 10-25.

LONGARAY, E. A. Globalização, antiimperialismo e o ensino de inglês na era pósmoderna. 2009. Tese (Doutorado em Estudos da Linguagem) Universidade Federal do Rio Grande do Sul, Porto Alegre.

LONGARAY, E. A.; LIMA, M. S. Os vários nomes do inglês na era global. Revista do Gelne, Teresina, v. 12, n. 1, p. 38-53, 2010.

MENONCIN, C.; VON BORSTEL, C. N. A competência comunicativa na língua inglesa por funcionários em duas empresas comerciais. In: ENCONTRO DO CELSUL, 10., 2012, Cascavel. Anais... Cascavel: UNIOESTE, 2012. p. 1-10.

MESQUITA, D. N. C.; MELLO, H. A. B. Sociedade global, englishes e bilinguismo glocal. Polifonia, Cuiabá, v. 13, n. 13, p. 45-58, 2007.

MOITA LOPES, L. P. Inglês no mundo contemporâneo: ampliando oportunidades sociais por meio da educação. In: INTERNATIONAL RESEARCH FOUNDATION FOR ENGLISH LANGUAGE EDUCATION - TIRF, 2005, São Paulo. Texto base... São Paulo, 2005. Mimeo.

MOITA LOPES, L. P. Inglês e globalização em uma epistemologia de fronteira: ideologia lingüística para tempos híbridos. DELTA, São Paulo, v. 24, n. 2, p. 309-340, 2008.

MOTTER, R. M. B.; CATAPAN, A. H. A formação do professor de inglês no contexto do idioma como língua global. Educere et Educare, Cascavel, v. 6, n. 12, p. 53-65, jul./dez. 2011. 
MOTT'-FERNANDEZ, C.; FOGAÇA, F. C. Inglês como língua internacional na universidade: rejeição e objeto de desejo. Linguagem \& Ensino, Pelotas, v. 12, n. 1, p. 195-225, jan./jun. 2009.

NUNES, Z. A. A. Afinal, que história é essa de inglês internacional? Caderno Seminal Digital, Rio de Janeiro, v. 6, n. 6, p. 95-108, jul./dez. 2006.

PARK, J. S.; WEE, L. A practice-based critique of English as a lingua franca. World Englishes, Oxford, v. 30, n. 3, p. 360-374, Sep. 2011.

PEDERSON, M. English as a lingua franca, world englishes and cultural awareness in the classroom. In: GIMENEZ, T.; CALVO, L. C. S.; EL KADRI, M. S. (Orgs.). Inglês como língua franca: ensino-aprendizagem e formação de professores. Campinas: Pontes, 2011. p. 59-85.

PESCADOR, C. M. Ações de aprendizagem empregada pelo nativo-digital para interagir em redes hipermidiáticas tendo o inglês como língua franca. 2010. Dissertação (Mestrado em Educação) - Universidade de Caxias do Sul, Caxias do Sul.

PRODROMOU, L. Implications for ELF. In: PRODROMOU, L. English as a lingua franca: a corpus-based analysis. London: Continuum, 2008.

PRODROMOU, L. Is ELF a variety of english? English Today, Cambridge, v. 23, n. 2, p. 47-53, Apr. 2007.

RAJAGOPALAN, K. A exposição de crianças ao inglês como língua estrangeira: o papel emergente do World English. Trabalhos em Linguistica Aplicada - TLA, Campinas, v. 48, n. 2, p. 185-196, jul./dez. 2009.

RAJAGOPALAN, K. O "World English": um fenômeno muito mal compreendido. In: GIMENEZ, T.; CALVO, L. C. S.; EL KADRI, M. S. (Orgs.). Inglês como lingua franca: ensino-aprendizagem e formação de professores. Campinas: Pontes, 2011. p. 45-57.

RAJAGOPALAN, K. World English or World Englishes? Does it make any difference? International Journal of Applied Linguistics, Oslo, v. 22, n. 3, p. 374-391, Nov. 2012.

REIS, F. S.; CRUZ, N. C. (Un)intelligibility in the context of English as a Lingua Franca: A study with French and Brazilian Speakers. Intercâmbio, São Paulo, v. 22, p. 35-55, 2010. 
ROCHA, C. H.; SILVA, K. A. World English no contexto do ensino fundamental-1 público. In: GIMENEZ, T.; CALVO, L. C. S.; EL KADRI, M. S. (Orgs.). Inglês como língua franca: ensino-aprendizagem e formação de professores. Campinas: Pontes, 2011. p. 253-292.

SALLES, M. R.; GIMENEZ, T. Ensino de inglês como língua franca: uma reflexão. BELT Journal, Porto Alegre, v. 1, n. 1, p. 26-33, jan./jul. 2010.

SALOMÃO, A. C. B. Vizinhança global ou proximidade imposta? Impactos da comunicação intercultural mediada por computador sobre o papel da cultura no ensino de língua inglesa. DELTA, São Paulo, v. 27, n. 2, p. 235-256, 2011.

SANTOS, S. M. A. Relações culturais internacionais e teoria crítica: estudando a legitimação do inglês como língua internacional. In: SIMPÓSIO EM RELAÇÕES INTERNACIONAIS DO PROGRAMA DE PÓS-GRADUAÇÃO EM RELAÇÕES INTERNACIONAIS SANTIAGO DANTAS, 2007, São Paulo. Anais... São Paulo: UNESP; UNICAMP; PUC-SP, 2007. p. 1-26.

SARNIGHAUSEN, V. C. R. Revisão sistemática e metassíntese: medições de gases de efeito estufa (GEE) emitidos pela pecuária bovina brasileira. 2011. Tese (Doutorado em Física do Ambiente Agrícola) - Escola Superior de Agricultura Luiz de Queiroz, Piracicaba.

SCHMITZ, J. R. "To ELF or not to ELF?” (English as a lingua franca): that's the question for applied linguistics in a globalized world. RBLA, Belo Horizonte, v. 12, n. 2, p. 249-284, 2012.

SCHÜTZ, R. O inglês como língua internacional. 2005 (atual. 3 jul. 2010). Disponível em: <http://www.sk.com.br/sk-ingl.html>. Acesso em: 3 jul. 2012.

SEIDLHOFER, B. Closing a conceptual gap: the case for a description of English as a lingua franca. International Journal of Applied Linguistics, Oslo, v. 11, n. 2, p. 133-158, 2001.

SEIDLHOFER, B. Research perspectives on teaching English as a lingua franca. Annual Review of Applied Linguistics, Cambridge, v. 24, p. 209-239, 2004. 
SEIDLHOFER, B. Understanding English as a lingua franca. Oxford: OUP, 2011.

SHOEMAKER, A. Regionalismo e identidade cultural: o inglês como língua internacional. Antares, Caxias do Sul, v. 3, n. 5, p. 20-37, jan./jun. 2011.

SIFAKIS, N. The education of teachers of English as a lingua franca: a transformative perspective. International Journal of Applied Linguistics, Oslo, v. 17, n. 3, p. 355-375, 2007.

SILVA, E. R. O conceito de "world englishes" em um livro didático de inglês utilizado na escola pública. Anais do Seta, Campinas, v. 5, p. 280-291, 2011.

SILVA, H. M. Língua franca no Brasil: inglês, globês ou inglês brasileiro? Veredas Favip, Revista Eletrônica de Ciências, Campina Grande, v. 2, n. 1/2, p. 35-42, jan./dez. 2009.

SILVA, J. M. Implicações culturais e didáticas do inglês como língua internacional: o livro didático. 2012. Dissertação (Mestrado em Linguagem e Educação) Universidade de São Paulo, São Paulo.

SILVA, V. E. S. A interculturalidade nos livros didáticos de inglês. Tabuleiro de Letras, Salvador, n. 3, p. 1-18, dez. 2011.

SILVEIRO, A. Ensino de pronúncia e inglês para aviação: uma interseção possível e necessária. In: ENCONTRO DO CELSUL, 10., 2012, Cascavel. Anais... Cascavel: UNOESTE, 2012. p. 1-11.

SIQUEIRA, D. S. P. Inglês como lingua internacional: por uma pedagogia intercultural. 2008. Tese (Doutorado em Letras) - Universidade Federal da Bahia, Salvador.

SIQUEIRA, D. S. P. Inglês como língua franca: o desafio de ensinar um idioma desterritorializado. In: GIMENEZ, T.; CALVO, L. C. S.; EL KADRI, M. S. (Orgs.). Inglês como língua franca: ensino-aprendizagem e formação de professores. Campinas: Pontes, 2011. p. 87-115.

SIQUEIRA, D. S. P. O desenvolvimento da consciência cultural crítica como forma de combate à suposta alienação do professor brasileiro de 
inglês. Revista Inventário, Salvador, v. 4, p. 1-27, jul. 2005. Disponível em: $<$ http://www.inventario.ufba.br/04/pdf/ssiqueira.pdf $>$. Acesso em: 3 jul. 2012.

SIQUEIRA, D. S. P.; ANJOS, F. A. Ensino de inglês como língua franca na escola pública: por uma crença no seu (bom) funcionamento. Muitas Vozes, Ponta Grossa, v. 1, n. 1, p. 127-149, 2012.

SKYBINA, V. English across cultures: adapting to new realities. Ilha do Desterro, Florianópolis, v. 1, n. 50, p. 127-154, jan./jul. 2006.

SOUZA, A. G. F.; BARCARO, C. F.; GRANDE, G. C. As representações de alunas-professoras de um curso de letras sobre o estatuto do inglês como língua franca. In: GIMENEZ, T.; CALVO, L. C. S.; EL KADRI, M. S. (Orgs.). Inglês como língua franca: ensino-aprendizagem e formação de professores. Campinas: Pontes, 2011. p. 193-220.

UR, P. English as a lingua franca: a teacher's perspective. Cadernos de Letras, Rio de Janeiro, v. 2, n. 27, p. 85-92, dez. 2010.

ZACCHI, V, J. Discursos da Globalização nas vozes de professores e professoras de língua inglesa. Trabalhos em Linguistica Aplicada - TLA, Campinas, v. 45, n. 1, p. 9-27, jan./jun. 2006.

Recebido em: 17/01/2014 Aceito em: 13/05/2014 